\title{
SOSYO-EKONOMIK FAKTÖRLERIN SUÇ ÜZERINE ETKISI: DÜZEY-2 BÖLGELERI MEKÂNSAL PANEL VERi ANALIZi
}

\author{
Havva GÜLTEKIN ${ }^{1}$, Adil OĞUZHAN²
}

Öz

Suç olayları çeşitli sosyo-ekonomik faktörlerden etkilenmekte olup bu faktörlerin bilinmesi ve dolayısıyla bu eğilimlerin doğru bir biçimde anlaşılması, suçla mücadele programlarının doğru şekilde yürütülmesi açısından önem arz etmektedir. Bu araştırmanın örneklemi 2008-2018 dönemine ait Türkiye Düzey2 bölgelerinin suç sayıları ve suç sayılarını belirleyen ekonomik ve demografik faktörlerden oluşmaktadır. Suç değişkenleri arasından toplam suçlar içerisinde en fazla paya sahip değişkenler örnekleme alınmıştır. Bu değişkenler hırsızlık ve yaralama suçlarını içermektedir. Suç sayılarını etkileyen faktörler ise kişi başı gayrisafi yurtiçi hâsıla, işsizlik oranı, genç nüfus oranı, kentleşme oranı, bölgelerin aldığı göç sayıları ve okuma-yazma bilmeyen nüfusun toplam nüfusa oranı olarak dikkate alınmıştır. Çalışmada dengeli panel veri seti kullanılarak, iki farklı ekonometrik model kurulmuştur. Hırsızlık suçu modelinde göç değişkeni dışında tüm değişkenlerin hırsızlık suçunu açıklamada anlamlı olduğu belirlenmiştir. Yaralama suçu modelinde yalnızca kişi başına gayri safi yurtiçi hâsıla ve okuma yazma bilmeyen nüfus oranı değişkenlerinin yaralama suçunu açıklamada istatistiksel olarak anlamlı faktörler olduğu belirlenmiştir.

Anahtar Kelimeler: Suç, Mekânsal Panel Veri Analizi, Düzey2 Bölgeleri

JEL SInıflandırması: C13, C23, K42

\section{THE EFFECT OF SOCIO-ECONOMIC FACTORS ON CRIME: LEVEL-2 REGIONS SPATIAL PANEL DATA ANALYSIS}

\begin{abstract}
The crime events are affected by several socio-economic factors. For this reason, it is important to know these factors, to understand these trends correctly and to carry out anti-crime programs correctly. The study covers the period from 2008 to 2018 annually and NUTS Level 2 Regions are considered. The variables with the largest share in total crimes are included in the sample. These variables include theft and injury crimes. Moreover, in this study the per capita gross domestic product, the unemployment rate, the illiterate population, the number of immigration received by regions, the proportion of young population and urbanization rate are considered as variables that affecting crime events. To determine the relationship between crime and the independent variables, two different econometric model is established by using the balanced panel data set. In the theft crime model, it is been determined that all variables except the migration variable are statistically significant in explaining the theft crime. In the injury crime model, it is been determined that only per capita gross domestic product, and the rate of illiterate population are statistically significant in explaining injury crime.
\end{abstract}

Keywords: Crime, Spatial Panel Data Analysis, NUTS-2 Regions

JEL Classification: C13, C23, K42

\footnotetext{
${ }^{1}$ Arş. Gör. Dr. Havva GÜLTEKIN, Trakya Üniversitesi, Iktisadi ve Idari Bilimler Fakültesi, Ekonometri Bölümü, Edirne, Türkiye, havvagultekin@trakya.edu.tr, ORCID: 0000-0002-3157-4635

2 Prof. Dr. Adil OĞUZHAN, Trakya Üniversitesi, Iktisadi ve Idari Bilimler Fakültesi, Ekonometri Bölümü, Edirne, Türkiye, adiloguzhan@trakya.edu.tr, ORCID: 0000-0003-2475-6892
} 


\section{Giriş}

Suç olgusu, bir toplumda hem bireyleri hem de ülkeyi ilgilendiren önemli konulardan biridir. Kanunlara veya bireylere karşı işlenen bu suçlar çok geniş bir yelpazede değerlendirilebilmekte ve yol açacağı sonuçlar da benzer şekilde büyük ölçüde problemlere neden olabilmektedir.

Suçun önemini ele alan çalışmasında Glaeser (1999) suçun, çoğu gelişmiş ülkede üzerinde odaklanılması gereken önemli bir sosyal sorun olduğunu ve suç faaliyetleri ile mücadele etmek için harcanan zamanın, daha verimli konulara harcanabileceğini savunarak suçun bir ülke için ne derece sosyal ve ekonomik bir kayıp olduğunu vurgulamaktadır.

Dolayısıyla suç eylemlerinin neden olacağı sonuçlar yalnızca suça maruz kalan kişiler üzerinde değil, tüm toplumda yaşayan kişiler üzerinde suç korkusu, psikolojik sorunlar, düşük yaşam kalitesi gibi etkiler yaratabilmesinin yanı sıra, ülke açısından da sosyal güvenlik, zaman kaybı, suçla mücadelede hükümet harcamalarının artması gibi ülkede çeşitli sosyo-ekonomik maliyetlere yol açabilecek büyük bir sosyal sorundur (Ishak, 2017:608).

Suç oranları ülkeler ve bölgeler arasında büyük farklılıklar göstermekle beraber ceza ve şiddet içeren bu davranışların öneminden dolayı, son yıllarda bu konuda yapılan çalışmaların artmasına ve yoğun tartışmalara neden olmuştur (Baharom, 2009:55).

Türkiye' de de suç oranları yıllar içerisinde sürekli bir artış göstermiştir. 2018 yılında 2006 yılına göre suç sayısı yaklaşık 3,5 kat artış göstererek 266.889 kişi olarak kaydedilmiştir. Aynı şekilde 2018 yılında bir önceki yıla göre suçlu sayısı \%23,7 oranında bir artış göstermiştir. Toplam suç oranları bakımından Türkiye'de suç oranı en yüksek iller Kilis, Edirne, Aydın iken en düşük suç oranına sahip iller Bayburt, Gümüşhane ve Çankırı illeri olarak kayıt edilmiştir (TÜIK, Bölgesel istatistikler veri tabanı). Grafik 1'de Türkiye'nin yıllar itibariyle suç seyri verilmiştir.

Grafik 1: Türkiye'de Yıllar İtibariyle Suç Sayısının Seyri

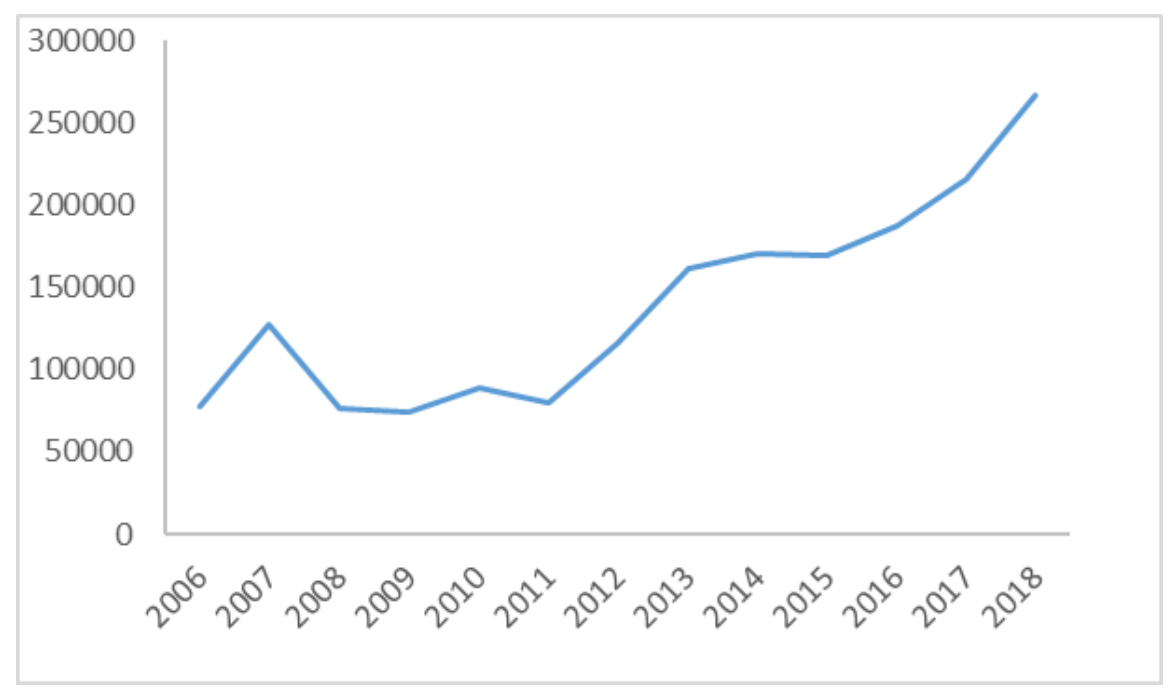

Grafik 1'de 2011 yılına kadar suç sayılarının ortalama aynı seviyelerde izlediği bu yıldan sonra ise sürekli bir artış gösterdiği açıkça söylenebilmektedir.

Türkiye'de işlenen suçlar türlerine göre değerlendirildiğinde ise en yüksek payı hırsızlık suçu $(\% 16,98)$ oluşturmakta iken, yaralama suçu $(\% 12,34)$ suçlar içerisinde ikinci en yüksek payı oluşturmaktadır.

Literatürde suçun çeşitli türleri ve diğer pek çok sosyo-ekonomik değişken arasındaki ilişkiyi incelemeye yönelik çalışmalar yapılmıştır (Entorf, H. ve Spengler H. 2000; Lombardo ve Falcone, 2011; Baharom, 2009; Tunca, 2019; Akdi 2014;Brosnan, 2018). 
Grafik 2: Türkiye'de Suçların Türlerine Göre Dağııımı

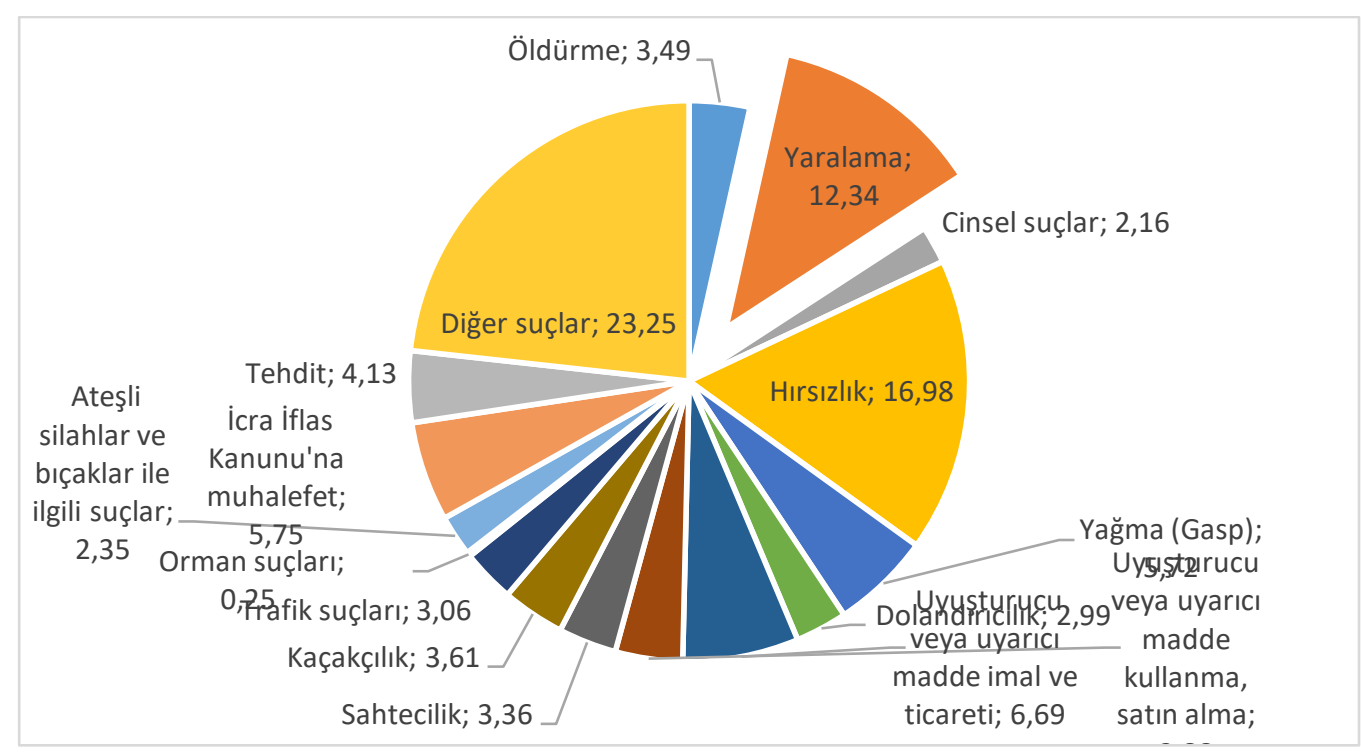

Ancak dikkat çekici bu istatistiklere ve suç literatüründe artan ilgiye rağmen Türkiye literatüründe suç olgusunu açıklamaya yönelik çalışmaların sayısı yetersiz kalmaktadır. Bu nedenle bu çalışma gelişmekte olan ülke olarak Türkiye için literatürdeki bu boşluğu doldurmayı amaçlamıştır.

Suç olayları, öldürme, yaralama, cinsel suçlar, hakaret, kişiyi hürriyetinden yoksun bırakma, yağma, dolandırıcılık, uyuşturucu ve madde kullanımı, uyuşturucu ve madde imal ve ticareti, sahtecilik, kötü muamele, zimmet, rüşvet, kaçakçılık, trafik suçları, orman suçları, ateşli silahlar ve bıçaklar ile ilgili suçlar, icra iflas kanununa muhalefet, askeri ceza kanununa muhalefet, tehdit, mala zarar verme, görevi yaptırmamak için direnme, ailenin korunması tedbirine aykırılık gibi farklı şekillerde ortaya çıkmaktadır (TÜiK). Farklı birçok şekilde ortaya çıkan bu suçların nedenleri de şüphesiz farklı nedenlerden kaynaklanacaktır. Bu nedenle suç olaylarını etkileyen faktörler belirlenirken bu olayları toplu olarak ele almak hatalı sonuçlara neden olabilecektir.

Bu sebeple çalışmada toplam suçlar içerisinde en fazla paya sahip hırsızlık ve yaralama suçları ele alınarak iki farklı model çerçevesinde değerlendirme yapılmıştır. Çalışmada kullanılan veriler TÜik bölgesel istatistikler veri tabanından elde edilmiş, ekonomik ve sosyal olarak birbirine benzerlik gösteren illerin bir arada değerlendirildiği Düzey2 bölgeleri ele alınmıştır. Türkiye, İstatistiki Bölge Birimleri Sınıflaması Düzey2 (IBBS-Düzey2)'e göre 26 ayrı bölgeye ayrılmıştır. 20082018 dönemini kapsayan çalışmada suç oranlarını etkileyen sosyoekonomik faktörler olarak kişi başı gayri safi yurtiçi hâsıla, işsizlik oranı, genç nüfus oranı, kentleşme oranı, bölgelerin aldığı göç sayısı ve okuma yazma bilmeyen nüfusun toplam nüfusa oranı değişkenleri değerlendirilmiştir. Çalışmada birbirine mekânsal olarak yakın olan birimlerin birbirini etkileyebileceğinden bu etkileri dikkate alan mekânsal panel regresyon modellerinden faydalanılmıştır.

Çalışmanın bundan sonraki bölümünde söz konusu literatür özetlenmiş olup, üçüncü bölümde çalışmada kullanılan veri seti ve analiz tanıtılmıştır. Dördüncü bölümde analiz sonuçlarına yer verilmiş son bölümde ise sonuçlar tartışılmıştır.

\section{Literatür Özeti}

Suç ve suçu etkilediği düşünülen çeşitli sosyo-ekonomik faktörler literatürde birçok araştırmacı tarafından incelemeye konu olmuştur. Ancak incelenen değişkenler açısından tutarlı sonuçlar elde edilememiştir. Örneğin suç üzerinde etkili olduğu düşünülen işsizlik değişkeninin suç üzerinde pozitif etkisi olduğunu tespit eden çalışmalar mevcut iken, işsizliğin suç üzerinde negatif etkisinin olduğunu tespit eden çalışmalar da mevcuttur. 
Entorf ve Spangler (2000) çalışmalarında ekonomik ve sosyo-demografik değişkenlerin yanında caydırıcılık değişkenini de kullanarak suç ile ilişkisini değerlendirmiştir. Elde ettikleri sonuçlar caydırıcılığın mülkiyet suçları üzerinde önemli etkisinin olduğunu göstermiş iken, kişiye karşı işlenen suçlar üzerinde önemli etkisi bulunmamıştır. Ekonomik değişkenler ile suç arasında da ilişki tespit edilmiş ve sosyo-demografik değişkenlerinde suç oranları üzerinde önemli etkileri olduğu bulunmuştur. Gould (2002) ise 1979-1989 dönemine ait panel veri setini kullanarak yaptığı çalışmasında ücret ve işsizliğin suç üzerinde önemli etkisinin olduğunu ortaya koymuştur. Bukenya (2006) regresyon analizini kullanarak suç ve sosyo-ekonomik değişkenler arasındaki ilişkiyi incelemiştir. Elde ettiği sonuçlar çerçevesinde eğitim, işsizlik, polis hacamaları gibi sosyo-ekonomik değişkenlerin suç üzerinde anlamlı etkilerinin olduğunu göstermiştir. Baharom ve Habibullah (2009) ise çalışmasında Malezya'da 1973-2003 dönemi gelir eşitsizliği ve suç arasındaki nedenselliği incelemişlerdir. Otoregresif Dağıtıımış Gecikme modeli kullanılarak yapılan çalışmada gelir eşitsizliği ile toplam suç, şiddet suçu, mal suçu, hırsızlık suçlarının hiçbiri ile anlamlı bir ilişkisi olmadığını belirtmişlerdir. Ata (2011) ücret ve işsizliğin suç üzerindeki etkisini 27 Avrupa Birliği ülkesi için 2008 yılı verilerini kullanarak En Küçük Kareler Yöntemi ile analiz etmiştir. Çalışmada işsizliğin suç üzerinde istatistiksel olarak anlamlı ve pozitif bir etkisinin olduğunu, ücret düzeyinin suç üzerinde negatif yönlü fakat istatistiksel olarak anlamsız bir etkiye sahip olduğunu belirlemiştir. Hugo vd. (2015) suçun bölgesel ekonomik büyüme üzerindeki etkisini Meksika da mekânsal panel veri modeli ile test etmişlerdir. 1997-2011 döneminde suçun özellikle de cinayet ve soygun suçlarının Meksika eyaletlerinin ekonomik büyümesi üzerinde olumsuz bir toplam etki yarattığını ve önemli yayılma etkilerinin var olduğunu göstermişlerdir. Shabbir vd. (2017) suç ve işgücü piyasası arasındaki ilişkiyi yüksek, orta ve düşük suç endeksine sahip ülkeler için Havuzlanmış EKKY ile 2012-2014 dönemi için analiz etmiştir. Sosyo-ekonomik, demografik ve caydırıcı değişkenleri kullanıldıkları çalışmada suç endeksi yüksek ülkelerde işsizlik ve kentleşmenin suç endeksi üzerinde önemli ve pozitif etkisinin olduğu, enflasyon, GSYH büyüme oranı, cezaevi nüfus oranı ile 18-24 yaş eğitimli nüfusun suç üzerinde önemsiz etkisinin olduğunu göstermişlerdir. Orta düzey suç endeksine sahip ülkelerde GSYH büyüme oranı ve kentleşmenin suç endeksi üzerinde önemli olumsuz etkiye sahip olduğu diğer taraftan, enflasyon, işsizlik, cezaevi nüfusu oranı ve 18-24 yaş eğitimli nüfusun suç üzerinde önemsiz etkiye sahip olduğu belirlenmiştir. Suç endeksinin düşük olduğu ülkelerde, işsizlik, kentleşme ve hapishane nüfus oranı işgücü piyasası suçlarından sorumlu olarak bulunmuştur. Ishak ve Bani (2017) 1990-2008 dönemi kapsayan çalışmasında Malezya'nın dört gelişmiş eyaletinde suçun sosyoekonomik ve sosyo-demografik belirleyicilerini incelemek amacıyla sabit etkili panel veri modelinden yararlanmışlardır. Çalışmanın bulguları kişi başına düşen GSYH, işsizlik oranı, nüfus yoğunluğu ve polis memurlarının sayısının toplam ve mülkiyet suçunun önemli belirleyicileri olduğunu ortaya koymuştur. Diğer taraftan şiddet içeren suçların, nüfus yoğunluğu ve yalnızca polis memurlarının sayısı ile ilişkili olduğu, hem nüfus yoğunluğunun hem de polis memurlarının sayısının mülkiyet ve şiddet suçlarının belirleyicisi olduğunu göstermiştir.

Bu konuda Türkiye için yapılan çalışmalar değerlendirildiğinde bu çalışmalardan biri Taş vd. (2014)'e aittir. Taş vd. Türkiye için 12 bölgeyi dikkate alarak yaptıkları çalışmalarında panel veri analizi ile 2008-2011 dönemini test etmişlerdir. Çalışma sonucunda kaba boşanma hızının suç oranları üzerinde pozitif, takipteki banka kredilerinin suç oranları üzerinde negatif bir etkisinin olduğunu göstermişlerdir. İşsizlik yalnızca bir modelde anlamlı bulunmuştur. Akdi vd. (2014) 2005:01-2011:12 dönemi aylık veriler ile enflasyon, işsizlik ve suç arasındaki nedensel ilişkiyi Türkiye için Engle-Granger (1987) ve Johansen Koentegrasyon yaklaşımını kullanarak test etmişlerdir. Çalışma neticesinde enflasyon, işsizlik ve suç arasında nedensel ilişki tespit edilmemiş iken, eğitim düzeyine göre işsizlik ile suç arasında iki yönlü nedensel ilişki bulunmuştur. Yamak vd. (2016), otuz ülkede 2000-2011 dönemi için hırsızlık suçu üzerinde etkili olan faktörleri araştırmışlardır. Çalışmanın sonucunda işsizlik oranı ve polis sayısı değişkenlerinin hırsızlık suçu üzerinde istatistiksel olarak anlamlı etkisinin olmadığı bulunmuştur. Diğer taraftan kişi başına gelir, eğitim harcaması ve nüfus yoğunluğunun hırsızlık suçu üzerinde negatif ve istatistiksel olarak anlamlı etkisinin olduğu belirlenmiştir. Yorulmaz ve Giray Yakut (2017), şiddet ve mülkiyet suçlarını Türkiye'de 81 il için incelemişlerdir. Elde edilen sonuçlara göre vergi oranlarının ve lise mezuniyet 
oranının şiddet suçları üzerinde anlamlı bir etkisinin olmadığı, göç oranlarındaki artışın ise şiddet suçlarında artışa neden olduğu, işsizlik oranındaki artışın şiddet suçlarını azalttığı belirlenmiştir. Mülkiyet suçları ile işsizlik oranı ve vergi oranları arasında aynı yönlü bir ilişkinin varlığı saptanmıştır. Kızılgöl ve Selim (2017) 2001-2010 dönemini ele almış ve bu çalışmada 28 AB ülkesi ve Türkiye'ye ait verileri kullanılarak sabit etkiler negatif binom modeli ile incelemişlerdir. Kişi başına düşen GSYH, işsizlik oranı ve şehirleşmenin toplam suç sayısı üzerinde pozitif ve önemli etkisinin olduğunu diğer taraftan okullaşma oranı ve polis sayısının suç sayısını azalttığı tespit edilmiştir. Büyüme oranı ve enflasyonun etkisinin ise önemli olmadığı belirtilmiştir. Bilgili ve Ulucak (2018) Türkiye dâhil 25 Avrupa ülkesinde gelir, işsizlik, eğitim düzeyi, refah endeksi, gelir eşitsizliği endeksi ve fiyat düzeyinin suç üzerindeki etkilerini 1993-2012 dönemi için panel veri yöntemi ile analiz etmişlerdir. Elde edilen sonuçlar kişi başına reel GSYH, eğitim ve refah endeksinin suç üzerinde negatif etkiye sahip olduğu, işsizlik, fiyat düzeyi ve gelir eşitsizliğinin pozitif etkiye sahip olduğunu göstermektedir. Elgin (2018) çalışmasında 1997-2015 döneminde 81 ilde cinayet oranının belirleyicilerini regresyon analizi kullanarak incelemiş ve kişi başı gelir, eğitim, polis oranı, nüfus ve işsizlik oranı ile cinayet oranı arasında anlamlı ilişkinin var olduğunu belirtmiştir. Tunca (2019) çalışmasında mali suçlar, hırsızlık ve şiddet suçları ile eğitim, gelir, işsizlik, göç ve hane halkı büyüklüğü gibi değişkenler arasındaki ilişkiyi araştırmıştır. Çalışmasında eğitim düzeyinin suç işleme eğilimi üzerinde anlamlı bir etkiye sahip olmadığı, göç ve hane halkı büyüklüğünün farklı suç türleri üzerinde anlamlı bir etkiye sahip olduğu, işsizlik ve gelir dağılımı adaletsizliğindeki artışın özellikle hırsızlık suçu üzerinde önemli bir etki yarattığı tespit edilmiştir. Gelir artışlarının yalnızca mali suçlar üzerinde pozitif bir etkisinin olduğu belirlenmiştir. Ayhan ve Bursa (2019) 28 AB üyesi ülkesini ele almış ve 1993-2016 dönemini kapsayan çalışmasında Westerlund eş bütünleşme testini kullanmıştır. Test sonuçlarına göre işsizlik oranından suç oranlarına doğru nedensellik olduğunu işsizlik oranlarındaki artışın suç oranlarını pozitif olarak etkilediğini doğrulamıştır. Yapılan çalışmalara ilişkin literatür Tablo 1'de özetlenmiştir.

Tablo 1: Literatür Özeti

\begin{tabular}{|c|c|c|c|c|}
\hline Yazar & Ülke & Dönem & Yöntem & Sonuç \\
\hline Entorf ve Spangler (2000) & Almanya & $\begin{array}{l}1975- \\
1996\end{array}$ & $\begin{array}{l}\text { Panel veri } \\
\text { Analizi }\end{array}$ & $\begin{array}{l}\text { Kentleşme, işsizlik, genç nüfus } \\
\text { ve yabancı nüfus suç sayını } \\
\text { pozitif olarak etkilemektedir. }\end{array}$ \\
\hline Gould (2002) & $A B D$ & $\begin{array}{l}1979- \\
1995\end{array}$ & $\begin{array}{ll}\text { Panel veri } \\
\text { Analizi }\end{array}$ & $\begin{array}{l}\text { Suç üzerinde ücret ve işsizlik } \\
\text { önemli etkiye sahiptir }\end{array}$ \\
\hline Bukenya (2006) & Alabama & 2003 & EKK & $\begin{array}{l}\text { Suç üzerinde Eğitim, işsizlik, } \\
\text { değişkenler önemli etkiye } \\
\text { sahiptir, polis sayısı harcaması } \\
\text { önemli değildir. }\end{array}$ \\
\hline $\begin{array}{l}\text { Baharom ve Habibullah } \\
\text { (2009) }\end{array}$ & Malezya & $\begin{array}{l}1973- \\
2003\end{array}$ & ARDL & $\begin{array}{l}\text { Gelir eşitsizliği suçu açıklamada } \\
\text { anlamlı değildir }\end{array}$ \\
\hline $\operatorname{Ata}(2011)$ & $27 \mathrm{AB}$ ülkesi & 2008 & EKK & $\begin{array}{l}\text { Suç üzerinde İşsizlik pozitif } \\
\text { etkiye sahip iken, ücret düzeyi } \\
\text { anlamlı etkiye sahip değildir }\end{array}$ \\
\hline Akdi vd. (2014) & Türkiye & $\begin{array}{l}\text { 2005:01- } \\
2011: 12\end{array}$ & $\begin{array}{l}\text { Granger, } \\
\text { Johansen }\end{array}$ & $\begin{array}{l}\text { Enflasyon ve işsizlik suç } \\
\text { üzerinde anlamlı etkiye sahip } \\
\text { değildir }\end{array}$ \\
\hline Hugo vd. (2015) & Meksika & $\begin{array}{l}1997- \\
2011\end{array}$ & $\begin{array}{l}\text { Panel veri } \\
\text { Analizi }\end{array}$ & $\begin{array}{lrr}\text { Suç ekonomik } & \text { büyüme } \\
\text { üzerinde olumsuz } & \text { etkiye } \\
\text { sahiptir } & & \\
\end{array}$ \\
\hline Ishak ve Bani(2017) & Malezya & $\begin{array}{l}1990- \\
2008\end{array}$ & $\begin{array}{lr}\text { Sabit } & \text { etkili } \\
\text { Panel } & \text { veri } \\
\text { modeli } & \end{array}$ & $\begin{array}{l}\text { Kişi başı GSYH, işsizlik oranı, } \\
\text { nüfus yoğunluğu, polis sayısı } \\
\text { suç üzerinde önemli etkiye } \\
\text { sahiptir }\end{array}$ \\
\hline
\end{tabular}


Tablo 1 Devamı: Literatür Özeti

\begin{tabular}{|c|c|c|c|c|}
\hline Yazar & Ülke & Dönem & Yöntem & Sonuç \\
\hline Shabbir vd.(2017) & $\begin{array}{l}\text { Suç endeksi } \\
\text { yüksek, } \\
\text { orta ve } \\
\text { düşük } \\
\text { toplam } 15 \\
\text { ülke }\end{array}$ & $\begin{array}{l}2012- \\
2014\end{array}$ & $\begin{array}{l}\text { Havuzlanmış } \\
\text { EKKY }\end{array}$ & $\begin{array}{l}\text { Her üç grupta işsizlik ve } \\
\text { kentleşme suç endeksi üzerinde } \\
\text { önemli etkiye sahipken, eğitimli } \\
\text { genç nüfus anlamsız olarak elde } \\
\text { edilmiştir. }\end{array}$ \\
\hline Taş vd.(2014) & Türkiye & $\begin{array}{l}2008- \\
2011\end{array}$ & $\begin{array}{l}\text { Panel veri } \\
\text { Analizi }\end{array}$ & $\begin{array}{l}\text { Kaba boşanma hızı, takipteki } \\
\text { banka kredileri önemli, işsizlik } \\
\text { önemli değildir }\end{array}$ \\
\hline Yamak vd. (2016) & 30 ülke & $\begin{array}{l}2000- \\
2011\end{array}$ & $\begin{array}{l}\text { Panel veri } \\
\text { Analizi }\end{array}$ & $\begin{array}{l}\text { İşsizlik oranı, polis sayısı hırsızık } \\
\text { suçu üzerinde anlamlı değil, kişi } \\
\text { başı gelir, eğitim harcaması, } \\
\text { nüfus yoğunluğu negatif etkiye } \\
\text { sahiptir }\end{array}$ \\
\hline $\begin{array}{l}\text { Yorulmaz ve Giray Yakut } \\
\text { (2017) }\end{array}$ & Türkiye 81 il & 2000 & Path Analizi & $\begin{array}{l}\text { İşsizlik ve göç oranı şiddet suçu } \\
\text { üzerinde anlamlı iken vergi } \\
\text { oranı ve lise mezuniyet oranı } \\
\text { anlamsızdır. }\end{array}$ \\
\hline Kızılgöl ve Selim (2017) & $28 \mathrm{AB}$ ülkesi & $\begin{array}{l}2001- \\
2010\end{array}$ & $\begin{array}{l}\text { Sabit Etkiler } \\
\text { Negatif } \\
\text { Binom Modeli }\end{array}$ & $\begin{array}{l}\text { Kişi başına düşen GSYH, işsizlik } \\
\text { oranı ve şehirleşme suç sayısını } \\
\text { pozitif, okullaşma oranı ve polis } \\
\text { sayısı negatif olarak } \\
\text { etkilemektir. } \\
\text { Büyüme oranı ve enflasyonun } \\
\text { istatistiksel olarak anlamlı } \\
\text { değildir. }\end{array}$ \\
\hline Bilgili ve Ulucak (2018) & $\begin{array}{l}25 \text { Avrupa } \\
\text { ülkesi }\end{array}$ & $\begin{array}{l}1993- \\
2012\end{array}$ & $\begin{array}{l}\text { Panel veri } \\
\text { yöntemi }\end{array}$ & $\begin{array}{l}\text { Kişi başına reel GSYH, eğitim ve } \\
\text { refah endeksi suç sayısını } \\
\text { negatif, işsizlik, fiyat düzeyi ve } \\
\text { gelir eşitsizliği ise pozitif olarak } \\
\text { etkilemektedir. }\end{array}$ \\
\hline Elgin (2018) & Türkiye 81 il & $\begin{array}{l}1997- \\
2015\end{array}$ & $\begin{array}{l}\text { Panel veri } \\
\text { analizi }\end{array}$ & $\begin{array}{l}\text { Kişi başı gelir, eğitim, polis } \\
\text { oranı, nüfus ve işsizlik oranı } \\
\text { değişkenlerinin cinayet oranı } \\
\text { üzerinde anlamlı etkisi vardır }\end{array}$ \\
\hline Tunca (2019) & Türkiye 81 il & $\begin{array}{l}2008- \\
2014\end{array}$ & $\begin{array}{l}\text { Panel veri } \\
\text { Analizi }\end{array}$ & $\begin{array}{l}\text { Göç ve hane halkı büyüklüğü } \\
\text { değişkenleri mali suçlar, } \\
\text { hırsılık ve şiddet suçlarını } \\
\text { etkilemekte iken, eğitim düzeyi } \\
\text { ise suç üzerinde bir etkiye sahip } \\
\text { değildir. }\end{array}$ \\
\hline Ayhan ve Bursa (2019) & $28 \mathrm{AB}$ & $\begin{array}{l}1993- \\
2016\end{array}$ & $\begin{array}{l}\text { Westerlund } \\
\text { eş } \\
\text { bütünleşme } \\
\text { testi }\end{array}$ & $\begin{array}{l}\text { İşsizlik oranlarındaki artış suç } \\
\text { oranlarını artırmaktadır }\end{array}$ \\
\hline
\end{tabular}

\section{Veri Seti ve Yöntem}

Bu çalışmada 2008-2018 dönemi İBBS (Düzey 2) bölgeleri için elde edilen değişkenlerden oluşan panel veri seti kullanılmıştır. Farklı suç tanımları arasından toplam suçlar içerisinde en fazla paya sahip olarak hırsızlık ve yaralama suçları değişkenleri ele alınmıştır. Bölgeler düzeyinde bağımlı değişken olarak hırsızlık değişkeni, hırsızlık suçundan cezaevine giren hükümlü sayısını, yaralama değişkeni ise yaralama suçundan cezaevine giren hükümlü sayısını ifade etmektedir. Bağımsız değişken olarak suç olaylarını etkilediği düşünülen kişi başına gayrisafi yurtiçi hâsıla, işsizlik oranı, genç nüfus oranı, kentleşme oranı, bölgelerin aldığı göç sayısı ve okuma yazma bilmeyen nüfusun 
toplam nüfusa oranı değişkenleri ele alınmıştır. Tüm değişkenler TÜik Bölgesel İstatistikler veri tabanından derlenmiştir. Düzey-2 bölgeleri ve kapsadığı iller Tablo 2'de verilmiş iken çalışmada kullanılan değişken ve tanımları Tablo 3'te verilmiştir.

Tablo 2: ïBBS-Düzey2 Bölgeleri ve Kapsadığı iller

\begin{tabular}{|c|c|}
\hline KODU & BÖLGE \\
\hline TR10 & İstanbul \\
\hline TR21 & Tekirdağ, Edirne, Kırklareli \\
\hline TR22 & Balıkesir, Çanakkale \\
\hline TR31 & İzmir \\
\hline TR32 & Aydın, Denizli, Muğla \\
\hline TR33 & Manisa, Afyonkarahisar, Kütahya, Uşak \\
\hline TR41 & Bursa, Eskişehir, Bilecik \\
\hline TR42 & Kocaeli, Sakarya, Düzce, Bolu, Yalova \\
\hline TR51 & Ankara \\
\hline TR52 & Konya, Karaman \\
\hline TR61 & Antalya, Isparta, Burdur \\
\hline TR62 & Adana, Mersin \\
\hline TR63 & Hatay, Kahramanmaraş, Osmaniye \\
\hline TR71 & Kırıkkale, Aksaray, Niğde, Nevşehir, Kırşehir \\
\hline TR72 & Kayseri, Sivas, Yozgat \\
\hline TR81 & Zonguldak, Karabük, Bartın \\
\hline TR82 & Kastamonu, Çankırı, Sinop \\
\hline TR83 & Samsun, Tokat, Çorum, Amasya \\
\hline TR90 & Trabzon, Ordu, Giresun, Rize, Artvin, Gümüşhane \\
\hline TRA1 & Erzurum, Erzincan, Bayburt \\
\hline TRA2 & Ağrı, Kars, Iğdır, Ardahan \\
\hline TRB1 & Malatya, Elazığ, Bingöl, Tunceli \\
\hline TRB2 & Van, Muş, Bitlis, Hakkâri \\
\hline TRC1 & Gaziantep, Adıyaman, Kilis \\
\hline TRC2 & Şanlıurfa, Diyarbakır \\
\hline TRC3 & Mardin, Batman, Şırnak, Siirt \\
\hline
\end{tabular}

Kaynak: www.tuik.gov.tr

Tablo 3: Kullanılan Değişkenler ve Tanımları

\begin{tabular}{|c|c|}
\hline DEĞIŞKEN & TANIM \\
\hline HIRSIZLIK & $\begin{array}{l}\text { Hırsızlık suçundan ceza infaz kurumuna giren hükümlü sayısı } \\
\text { (1000 kişi başına düşen) }\end{array}$ \\
\hline YARALAMA & $\begin{array}{l}\text { Yaralama suçundan ceza infaz kurumuna giren hükümlü } \\
\text { sayısı (1000 kişi başına düşen) }\end{array}$ \\
\hline KBGSYH & Kişi başına Gayrisafi Yurtiçi Hâsıla (2009 bazlı) \\
\hline OKYB & $\begin{array}{l}6 \text { yaş ve üzeri okuma yazma bilmeyen nüfusun toplam nüfus } \\
\text { içindeki payı }\end{array}$ \\
\hline GOC & Alınan göç sayısı \\
\hline KENT & Kent nüfusunun toplam nüfusa oranı \\
\hline GENC & Genç nüfusun toplam nüfusa oranı \\
\hline ISZ & İşsizlik oranı \\
\hline
\end{tabular}

Ekonometrik araştırmalarda özellikle coğrafi bölgelerle çalışıldığında, gözlemler arasında mekânsal bağımlılık olabileceğinden bu bağımlıı̆̆ın göz ardı edilmesi tahmin sonuçlarının hatalı olmasına sebep olabilmektedir. Bu nedenle bu çalışmada söz konusu bağımlılığı dikkate alan mekânsal regresyon modellerinden faydalanılmıştır. 
Standart panel veri modelleriyle karşılaştırıldığında, mekânsal panel veri modelleri, mekânsal bağımlılık ve mekânsal yayılma etkilerini içermektedir. Ayrıca, yatay-kesit mekânsal regresyon modelleri ile karşılaştırıldığında, mekânsal panel veri modeli, mekânsal birimlerin bireysel heterojenligini daha iyi açıklayabilmekte ve tahmin hatalarının önemli ölçüde azalmasını sağlayabilmektedir (Elhorst, 2014).

Çalışmada ilk olarak mekânsal etkileri içermeyen standart panel veri modeli tahmin edilmiştir. Bu model mekânsal panel veri modellerinin tahmin sonuçları için bir temel olarak ya da tahmin sonuçlarının tutarılığını kontrol etmek için kullanılabilmektedir (Yang vd., 2017). Sabit etkilerle standart panel veri modeli (1) no'lu eşitlikte verildiği gibi tanımlanabilir;

$$
y_{i t}=x_{i t}^{\prime} \beta+\mu_{i}+\varepsilon_{i t}
$$

$y$ bağımlı değişkeni, i birimleri, t zaman boyutunu göstermektedir. $x_{i t}^{\prime} ; 1 * K$ Boyutlu açılayıcı değişken vektörü $\beta$ ise $K * 1$ boyutlu katsayı vektörüdür. $\mu_{i}$ birimlere özgü spesifik etkileri ve $\varepsilon_{i t}$ birim ve zamana göre değişmeyen hata terimlerini belirtmektedir. $\mu_{i}$ açıklayıcı değişken $x_{i t}$ ile korelasyonlu ise model sabit etkili panel veri modeli, $\mu_{i}$ hata terimi $\varepsilon_{i t}$ ile korelasyonlu ise model rassal etkili panel veri modeli olarak ifade edilmektedir.

Mekânsal etkileri içeren modeller değerlendirildiğinde ise bu modeller yatay kesit verileri için tanımlanabileceği gibi panel veri modelleri içinde tanımlanabilmektedir. Mekânsal regresyon modelleri; mekânsal gecikme modeli (SAR), mekânsal hata modeli (SEM), Genel Mekânsal Model (SAC) ve Mekânsal Durbin modellerini (SDM) içermektedir.

Sabit etkili panel veri modelleri için Mekânsal Gecikme Modeli (SAR) bağımlı değişkenin mekânsal yayılma etkisini dikkate almaktadır. $\rho$ mekânsal otoregresif katsayıyı göstermek üzere model (2) no'lu eşitlikte verildiği gibi yazılmaktadır.

$$
\begin{aligned}
& y_{i t}=\rho W y_{t}+x_{i t}^{\prime} \beta+\mu_{i}+\varepsilon_{i t} \\
& E\left(\varepsilon_{i t}\right)=0 \text { ve } E\left(\varepsilon_{i t} \varepsilon_{i t}^{\prime}\right)=\sigma^{2} I_{N} \\
& W y_{t}=\sum_{j=1}^{n} w_{i j} y_{i t}
\end{aligned}
$$

$\rho W y_{t}$; bağımlı değişkenin mekânsal gecikmesini, $\rho$ komşu mekânların bağımlı değişkeninin ilgili bölgenin bağımlı değişkeni üzerindeki etkisini gösteren mekânsal gecikme katsayısını ifade etmekte ve $|\rho|<1$ olarak elde edilmektedir.

Mekânsal Hata Modeli (SEM) mekânlar arasındaki bağımlılığın hatalar arasında gerçekleştiği modellerdir ve sabit etkili panel veri için (3) no'lu eşitlikte verildiği gibi ifade edilebilmektedir;

$$
\begin{aligned}
& y_{i t}=\alpha+\mu_{i}+X_{i t}^{\prime} \beta+u_{i t} \\
& u_{i t}=\lambda \sum_{i \neq j} w_{i j} u_{j t}+\varepsilon_{i t} \\
& \left(\varepsilon_{i t} \varepsilon_{i t}^{\prime}\right)=\sigma^{2} I_{N} .
\end{aligned}
$$

$\lambda \sum_{i \neq j} w_{i j} u_{j t}$ Mekânsal etkili hata terimi, $\lambda$ mekânsal hata otokorelasyon katsayısını, $\varepsilon_{i t}$ bağımsız özdeş dağılan hata terimlerini ifade etmektedir.

SAC modeli mekânsal gecikme ve mekânsal hatanın birlikte modelde yer aldığı modellerdir. Hem mekânsal gecikme hem de mekânsal hata terimlerinin bulunduğu bu model eşitlik (4)'te verildiği gibi yazılabilmektedir; 


$$
\begin{aligned}
& y_{i t}=\alpha+\mu_{i}+\rho \sum_{i \neq j} w_{i j} y_{j t}+X_{i t}^{\prime} \beta+u_{i t} \\
& u_{i t}=\lambda \sum_{i \neq j} w_{i j} u_{j t}+\varepsilon_{i t}
\end{aligned}
$$

Mekânsal ekonometrik modellerde var olabilecek mekânsal bağımlılık EKK tahmincilerinin sapmasızlık, tutarlılık ve etkinlik özelliklerinin kaybolmasına neden olabilmektedir. Bu nedenle bu modellerin tahmin edilmesinde En Çok Olabilirlik, Araç Değişkenler ya da Genelleştirilmiş Momentler Metotları yaygın olarak kullanılmaktadır (Anselin, 1988).

Mekânsal bağımlılı̆ın modelde ne şekilde yer alacağını belirlemek için çeşitli istatistiksel yöntemler mevcuttur. Moran I testi, Mekânsal hata bağımlılığı için Lagrange Çarpan Testi [LM (err)], Mekânsal gecikme bağımlılığı için Lagrange Çarpan Testi [LM (lag)] en çok kullanılan testlerdir (Moran, 1948).

Mekânsal bağımlılığın modele dâhil edilmesinde mekânsal ağılık matrisinden faydalanılmaktadır. Panel verilerde Mekânsal ağırlık matrisi yatay kesit verileri için $N * N$ boyutlu W matrisi iken panel verilerde $N * T$ boyutlu $W$ matrisi şeklinde gösterilmektedir. Uzaklığa veya yakınlığa dayalı olarak farklı ağırlık matrisleri mevcuttur. Bu çalışmada yaygın olarak kullanılan uzaklığa dayalı ROOK kriteri ile oluşturulan mekânsal ağırlık matrisi kullanılmıştır. Bu yöntemle oluşturulan ağırlık matrisinde, bölgeler komşu ise 1 , değil ise 0 değerini almaktadır. İşlem kolaylığı açısından genellikle satır toplamları 1'e eşit olacak şekilde standartlaştırma yapılmaktadır.

\section{Ampirik Bulgular}

Hırsızlık ve yaralama modeli olmak üzere iki farklı model tahminin yapıldığı çalışmada ilk olarak hırsızlık modeli tahmin edilmiştir. Mekânsal panel regresyon modeli tahmin edilmeden önce standart panel regresyon modeli ile tahmin edilmiş ve tahmin sonuçları Tablo 4 'te verilmiştir.

Tablo 4: Sabit ve Rassal Etkili Model Tahmin Sonuçları

\begin{tabular}{ccc}
\hline HIRSIZLIK & Sabit Etkili Model & Rassal Etkili Model \\
\hline KBGSYH & $0,385^{* * *}$ & $0,429 * * *$ \\
ISZ & $-0,002$ & $-0,003$ \\
KENT & $0,005^{* * *}$ & $0,005^{* * *}$ \\
GENC & $-0,052^{* * *}$ & $-0,014^{* *}$ \\
GOC & $-0,031$ & $-0,157^{* * *}$ \\
OKYB & $0,030^{* * *}$ & $0,030^{* * *}$ \\
Sabit & $-2,808^{* * *}$ & $-2,512^{* * *}$ \\
$R^{2}$ & 0,878 & 0,8671 \\
F testi & $304,54 * * *$ & $1425,38^{* * *}$ \\
Wald Testi & & \\
Hausman Testi & $486,69 * * *$ &
\end{tabular}

Tablo 4'te elde edilen sonuçlar çerçevesinde sabit etkiler panel modelinde işsizlik ve göç değişkenleri dışındaki tüm değişkenlerin hırsızlık değişkenini açıklamada istatistiksel olarak anlamlı olduğu bulunmuştur. $R^{2}$ değeri yaklaşık \%88 ve model anlamlı olarak tahmin edilmiştir. Rassal etkili model tahmin sonuçlarına göre ise yalnızca işsizlik değişkeninin istatistiksel olarak anlamsız olduğu, diğer tüm değişkenlerin hırsızlık suçu değişkenini açıklamada istatistiksel olarak anlamlı olduğu görülmüştür. Model tahmininden sonra yapılan Hausman test istatistiğine göre $H_{0}$ hipotezi reddedilmekte ve uygun modelin Sabit etkili model olduğuna karar verilmektedir. Bu nedenle işsizlik ve göç değişkenleri modelden çıkarılarak dirençli standart hatalarla sabit etkili panel veri modeli tahmin edilmiş ve sonuçlar Tablo 5'te verilmiştir. 
Tablo 5: Sabit Etkili Panel Veri Model Tahmin Sonuçları

\begin{tabular}{ccccc}
\hline HIRSIZLIK & Katsayı & St.hata & t istatistik & Olasılık \\
\hline KBGSYH & 0,373 & 0,028 & 13,340 & 0,000 \\
KENT & 0,005 & 0,001 & 4,340 & 0,000 \\
GENC & $-0,056$ & 0,016 & $-3,510$ & 0,002 \\
OKYB & 0,029 & 0,004 & 7,610 & 0,000 \\
Sabit & $-2,976$ & 0,442 & $-6,740$ & 0,000 \\
F istatistik & 104,49 & & & \\
$R^{2}$ & 0,8767 & & & \\
\hline
\end{tabular}

Sabit etkili panel veri modeli tahmin sonuçlarına göre kişi başı gayrisafi yurtiçi hâsıla, kentleşme oranı ve okuma yazma bilmeyenlerin oranı arttıkça hırsızlık suçunda artış meydana geleceği, genç nüfus oranındaki artışın ise hırsızlık sayısında azalışa neden olacağı söylenebilmektedir. Hırsızıı suçu değişkeninde meydana gelen değişimin yaklaşık \%88'i söz konusu değişkenlerden kaynaklanmaktadır.

Hırsızlık suçu modelinde mekânsal etkinin varlığını tespit etmek amacıyla Moran I, Lagrange Çarpanı ve LM hata testleri gerçekleştirilmiş ve bu testlerden elde edilen sonuçlar Tablo 6’da verilmiştir.

Tablo 6: Uygun Mekânsal Modelin Seçimi

\begin{tabular}{ccc}
\hline & Test İstatistiği & p-değeri \\
\hline Global Moran MI & 0,268 & 0,000 \\
Global Geargy GC & 0,698 & 0,000 \\
Global Getis-Ords go & $-0,268$ & 0,000 \\
Moran MI Error Test & 6,316 & 0,000 \\
LM Error(Burridge) & 38,105 & 0,000 \\
LM Error(Robust) & 266,385 & 0,000 \\
LM Lag(Anselin) & 166,172 & 0,000 \\
LM Lag(Robust) & 394,451 & 0,000 \\
LM SAC & 432,556 & 0,000 \\
LM SAC & 432,556 & 0,000 \\
\hline
\end{tabular}

Global Moran MI, Global Geargy GC, Global Getis-Ords go, Moran MI Error Test istatistiklerinde aşağıdaki hipotezler sınanmaktadır;

$$
\begin{aligned}
& \mathrm{H}_{0} \text { : Hatalarda mekânsal otokorelasyon yoktur } \\
& \mathrm{H}_{1} \text { : Hatalarda mekânsal otokorelasyon vardır }
\end{aligned}
$$

Elde edilen sonuçlar çerçevesinde $\alpha=0,05, \alpha=0,01$ ve $\alpha=0,10$ önem seviyesinde hatalarda mekânsal otokorelasyonun olmadığını ifade eden $H_{0}$ hipotezinin ret edildiği ve dolayısıyla mekânsal otokorelasyonun olduğu söylenebilmektedir.

Benzer şekilde LM Lag testi ile $\mathrm{H}_{0}$ : Mekânsal gecikme yoktur hipotezi sınanmaktadır. $\alpha=$ $0,05, \alpha=0,01$ ve $\alpha=0,10$ önem seviyesinde sıfır hipotezi ret edilmekte ve modelde mekânsal bağımlı değişkenin olduğu söylenebilmektedir. LM SAC istatistiği ile Mekânsal gecikme ve mekânsal hatanın varlığını birlikte varlığı test edilmektedir. Söz konusu test sonucu değerlendirildiğinde sıfır hipotezinin ret edildiği ve mekânsal hata ve mekânsal gecikmenin modelde var olduğu söylenebilmektedir. Sonuçlar bir bütün olarak değerlendirildiğinde uygun modelin genel mekânsal model (SAC) olduğuna karar verilmektedir. Ancak SAC model tahmininde mekânsal gecikme ve mekânsal otokorelasyon katsayılarının hesaplanıp yorumlanması sorunlu olduğundan SAC modelinin yanında Mekânsal Otokorelasyon ve Mekânsal hata modelleri de kullanılarak tahminler yapılmış ve sonuçlar Tablo 7'de verilmiştir. ilk olarak tahmin edilen modelde GOC değişkeni anlamsız bulunmuş ve bu nedenle bu değişken modelden çıkartılarak tekrar tahmin yapılmıştır. 
Tablo 7: Sabit Etkili Mekânsal Model Tahmin Sonuçları

\begin{tabular}{cccc}
\hline HIRSIZLIK & SAR & SEM & SAC \\
\hline KBGSYH & $0,146^{* * *}$ & $0,376^{* * *}$ & $0,099^{* * *}$ \\
ISZ & $-0,003^{* *}$ & $-0,002^{*}$ & $-0,003^{* *}$ \\
GENC & $-0,038^{* * *}$ & $-0,045^{* * *}$ & $-0,037^{* * *}$ \\
KENT & $0,002 * * *$ & $0,002^{* *}$ & $0,002^{* * *}$ \\
OKYB & $0,016^{* * *}$ & $0,016^{* * *}$ & $0,014^{* * *}$ \\
$\rho$ & $0,60 * * *$ & - & $0,705^{* * *}$ \\
$\lambda$ & - & $0,64 * * *$ & $-0,329 * * *$ \\
$R^{2}$ & $0,89 * * *$ & $0,86 * * *$ & $0,904 * * *$
\end{tabular}

Tahmin sonuçlarına göre her üç modelde de benzer sonuçlara ulaşılmış olup, model parametreleri değerlendirildiğinde kişi başı gayrisafi yurtiçi hâsıla, kentleşme oranı ve okuma yazma bilmeyen oranının hırsızık suçunu pozitif olarak etkilediği, dolayısıyla bu değişkenlerde meydana gelecek artışın hırsızlık suçunda artışa neden olacağı söylenebilmektedir. Diğer taraftan genç nüfus oranı ve işsizlik oranının hırsızlık suçunu negatif olarak etkilediği bu değişkenlerde meydana gelecek bir artışın hırsızlık suçunda azalışa neden olacağı söylenebilmektedir. Bu sonuçlar ilk izlenimde işsizlik oranının iktisadi beklentilere uygun olmadığını göstermesine karşılık, işsizlik oranının kırsal ve eğitim düzeyi düşük olanlardan daha çok yüksek eğitim düzeyine sahip kişiler tarafından olabileceği düşünüldüğünde sonucun tutarlı olduğu söylenebilecektir. Ele alınan değişkenler hırsızılk değişkenini yaklaşık \% 90 oranında açıklamaktadır. Modelde mekânsal gecikme katsayısı ve mekânsal otokorelasyon katsayısı pozitif ve istatistiksel olarak anlamlı bulunmuştur. Bu bir bölgenin hırsızlık sayısında meydana gelecek artışın komşu bölgedeki hırsızlık sayısında artışa neden olacağı anlamına gelmektedir. Bölgeler birbirlerinin hırsızlık sayılarını pozitif olarak etkilemektedir.

\section{Yaralama Modeli Tahmin Sonuçları}

Yaralama suçu modeli için öncelikle sabit ve tesadüfi etkileri içeren standart panel veri modeli tahmin edilmiş ve tahmin sonuçları Tablo 8' de verilmiştir.

Tablo 8: Sabit ve Rassal Etkili Model Tahmin Sonuçları

\begin{tabular}{ccc}
\hline YARALAMA & Sabit Etkili Model & Rassal Etkili Model \\
\hline KBGSYH & $0,154^{* * *}$ & $0,204^{* * *}$ \\
ISZ & $-0,007^{* * *}$ & $-0,009^{* * *}$ \\
KENT & $0,005^{* * *}$ & $0,004^{* * *}$ \\
GENC & $-0,022^{*}$ & $-0,009^{* *}$ \\
GOC & 0,033 & $-0,162^{* * *}$ \\
OKYB & 0,005 & 0,003 \\
Sabit & $-1,559^{* *}$ & 0,033 \\
$R^{2}$ & 0,695 & 0,668 \\
F testi & $96,69^{* * *}$ & \\
Wald Testi & & $499,16^{* * *}$ \\
Hausman Testi & $58,61^{* * *}$ & \\
Not: ${ }^{* * *} 0,01{ }^{* *} 0,05 * 0,10$ & &
\end{tabular}

Sabit etkileri içeren model tahmini incelendiğinde yaralama suçu üzerinde kişi başı gayrisafi yurtiçi hâsıla, işsizlik oranı ve kentleşme değişkeninin istatistiksel olarak anlamlı etkisinin olduğu, diğer taraftan genç nüfus oranı 0,10 anlam seviyesinde anlamlı iken alınan göç sayısı ve okumayazma bilmeyen değişkenlerinin yaralama suçu üzerinde istatistiksel olarak anlamlı etkisinin olmadığı söylenebilmektedir. Rassal etkili model tahminine göre ise okuma-yazma bilmeyen nüfus dışında tüm değişkenlerin yaralama suçu üzerinde anlamlı etkisinin olduğu söylenebilmektedir.

Model tahminleri yapıldıktan sonra uygun tahmincinin belirlenmesi amacıyla sabit ve rassal etkiler modelleri üzerinden Hausman testi yapılmıştır. Elde edilen hausman test sonucuna göre 
uygun modelin sabit etkili panel veri modeli olduğu belirlenmiş ve genç nüfus oranı, alınan göç sayısı ve okuma-yazma bilmeyen değişkenleri anlamsız bulunduğundan bu değişkenler modele dâhil edilmeden sabit etkili model tahmin edilmiştir.

Dirençli standart hatalar kullanılarak yapılan sabit etkili panel modeli tahmin sonuçları Tablo 9'da verilmiştir.

Tablo 9: Sabit Etkili Panel Modeli Tahmin Sonuçları

\begin{tabular}{ccccc}
\hline YARALAMA & Katsayı & St. hata & t istatistik & Olasılık \\
\hline KBGSYH & 0,162 & 0,020 & 7,950 & 0,000 \\
ISZ & $-0,007$ & 0,002 & $-4,710$ & 0,000 \\
KENT & 0,004 & 0,001 & 4,730 & 0,000 \\
Sabit & $-1,598$ & 0,163 & $-9,810$ & 0,000 \\
F istatistik & 85,35 & & & 0,000 \\
$R^{2}$ & 0,688 & & & \\
\hline
\end{tabular}

Sabit etkili model tahmin sonuçlarına göre kişi başı gayrisafi yurtiçi hâsıla ve kentleşme değişkeninde meydana gelecek bir artışın yaralama suçunda artışa neden olacağı, diğer taraftan işsizlik değişkeninde meydana gelecek artışın ise yaralama suçunda azalışa neden olabileceği söylenebilmektedir. Yaralama suçundaki değişimin yaklaşık \%69’u söz konusu değişkenler tarafından açıklanabilmektedir.

Yaralama modelinde mekânsal etkinin varlığını tespit etmek amacıyla Moran I, Lagrange Çarpanı ve LM hata testleri gerçekleştirilmiş ve bu testlerden elde edilen sonuçlar Tablo 10'da verilmiştir.

Tablo 10: Mekânsal Etkinin Testi

\begin{tabular}{ccc}
\hline & Test İstatistiği & p-değeri \\
\hline Global Moran MI & 0,461 & 0,000 \\
Global Geargy GC & 0,540 & 0,000 \\
Global Getis-Ords go & $-0,461$ & 0,000 \\
Moran MI Error Test & 10,813 & 0,000 \\
LM Error(Burridge) & 112,775 & 0,000 \\
LM Error(Robust) & 618,589 & 0,000 \\
LM Lag(Anselin) & 259,783 & 0,000 \\
LM Lag(Robust) & 765,597 & 0,000 \\
LM SAC & 878,373 & 0,000 \\
LM SAC & 878,373 & 0,000 \\
\hline
\end{tabular}

Moran I, Lagrange Çarpanı ve Lm Hata testlerine ait tüm test istatistikleri incelendiğinde sıfır hipotezinin ret edildiği dolayısıyla modelde hem mekânsal gecikme hem de mekânsal hatanın olduğu söylenebilmektedir. Genel Mekânsal Model (SAC) yanında SEM ve SAR modelleri de tahmin edilmiş ve tahmin sonuçları Tablo 11'de verilmiştir.

Tablo 11: Sabit Etkili Genel Mekânsal Model Tahmin Sonuçları

\begin{tabular}{cccc}
\hline YARALAMA & SAR & SEM & SAC \\
\hline KBGSYH & $0,045^{* * *}$ & $0,229^{* * *}$ & $0,126^{*}$ \\
ISZ & $-0,004^{* * *}$ & - & - \\
GENC & $-0,013^{*}$ & $-0,021^{* * *}$ & - \\
KENT & $0,001^{* * *}$ & - & - \\
OKYB & $0,005^{* *}$ & $0,008^{* * *}$ & $0,012^{* * *}$ \\
$\rho$ & $0,76^{* * *}$ & - & $-0,484$ \\
lambda & - & 0,800 & 0,935 \\
$R^{2}$ & 0,72 & - & 0,4645 \\
\hline
\end{tabular}

Yaralama modelinde kişi başı gayrisafi yurtiçi hâsıla ve okuma yazma bilmeyenlerin oranı değişkenlerinin bütün modellerde istatistiksel olarak anlamlı olduğu belirlenmiştir. Kişi başı 
gayrisafi yurtiçi hâsıla ve okuma yazma bilmeyenlerin oranı değişkeninde meydana gelecek bir artışın yaralama suçunda artışa neden olabileceği söylenebilmektedir. Modelde mekânsal gecikme ve mekânsal otokorelasyon katsayısı her üç modelde de pozitif ve anlamlı olarak bulunmuştur. Bu bir bölgenin yaralama suçları sayısında meydana gelecek artışın komşu bölgedeki yaralama suçları sayısında artışa neden olacağı anlamına gelmektedir. Bölgeler birbirlerinin yaralama suçu sayılarını pozitif olarak etkilemektedir.

\section{Sonuç}

Çalışmada mekânsal etkileri içeren panel veri modelleri kullanılarak Türkiye'de Düzey 2 bölgelerinde suç üzerinde etkili olan faktörler incelenmiştir. Değişik nedenlerin değişik suçlara yol açabileceği düşüncesinden dolayı çalışmada literatürde yaygın olarak değerlendirilenin aksine toplam suç sayısı değil toplam suçlar içerisinde en fazla paya sahip suçlar değerlendirmeye alınmıştır. Bu suçlar ülkemizde toplam suçlar içerisinde yaklaşık \%30'luk bir payı oluşturmakta olan hırsızlık ve yaralama suçlarını içermektedir.

Model tahminleri standart panel veri modeli ve mekânsal panel veri modelleri olarak iki farklı şekilde yapılmıştır. 2008-2018 dönemi yılık verileri kullanılarak hırsızlık ve yaralama olmak üzere iki farklı model tahmin edilmiştir. Hırsızlık değişkeninin ele alındığı Sabit etkili panel veri modeli ve mekânsal etkili panel veri modeli karşılaştırıldığında sabit etkili panel veri modelinde işsizlik oranı değişkeni anlamsız bulunmuş iken mekânsal etkili panel veri modelinde işsizlik değişkeninin katsayısı negatif ve istatistiksel olarak anlamlı elde edilmiştir. Diğer sonuçlar paralellik göstermekte olup, kişi başı gayrisafi yurtiçi hâsıla, kentleşme oranı ve okuma yazma bilmeyen oranının hırsızlık suçunu pozitif olarak etkilediği, genç nüfus oranının ise negatif olarak etkilediği belirlenmiştir. Göç değişkeninin her iki modelde de hırsızlık suçu üzerinde istatistiksel olarak anlamlı etkisi bulunamamıştır.

Yaralama modeli değerlendirildiğinde sabit etkili panel veri modelinde kişi başına gayrisafi yurtiçi hâsıla, işsizlik ve kentleşme değişkeni pozitif ve istatistiksel olarak anlamlı iken diğer değişkenler anlamlı olarak elde edilememiştir. Sabit etkili mekânsal panel veri modelinde SAR, SEM ve SAC modelleri genel olarak farklı sonuçlar vermiş olup kişi başına gayrisafi yurtiçi hâsıla ve okuma yazma bilmeyen değişkenleri her üç modelde de istatistiksel olarak anlamlı olarak elde edilmiştir. Modelde kişi başı gelir ve okuma yazma bilmeyen oranının yaralama suçunu pozitif olarak etkilediği tespit edilmiştir.

Elde edilen sonuçlar kişi başı gayrisafi yurtiçi hâsıla, kentleşme oranı ve okuma yazma bilmeyen oranının hırsızlık suçunu pozitif etkilemesi iktisadi beklentilerle uygun olup Ishak ve Bani (2017), Yorulmaz ve Giray Yakut (2017), Kızılgöl ve Selim (2017) çalışmalarını desteklemektedir. İşsizlik oranının hırsızıı suçunu negatif olarak etkilemesi, ilk izlenimde iktisadi beklentilerle uygun olmadığını düşündürmesine karşılık, işsizlik oranının kırsal ve eğitim düzeyi düşük olanlardan daha çok yüksek eğitim düzeyine sahip kişiler tarafından olabileceği düşünüldüğünde sonucun tutarlı olduğu söylenebilecektir.

\section{Kaynakça}

Akdi, Y., Karamanoğlu,Y.E ve Afşin Şahin, A. (2014). Unemployment by Education Status, Prices and Crime Relationship: Evidence from Turkey, Güvenlik Bilimleri Dergisi, 3(2), 119-143

Anselin, L. (1988). Spatial Econometrics: Methods and Model. London New York: Springer.

Ata, A.Y. (2011). Ücretler, İşsizlik ve Suç Arasındaki ilişski: Yatay-Kesit Analizi. Çalışma ve Toplum, 4, 113-134.

Ayhan, F. ve Bursa, N. (2019). Unemployment and Crime Nexus in European Union Countries: A Panel Data Analysis, Yönetim Bilimleri Dergisi /Journal of Administrative Sciences, 17(34), 465-484, DOI: https://doi.org/10.35408/comuybd.574808. 
Baharom, A.H.ve Habibullah, M.H. (2009). Crime and Income Inequality: The Case of Malaysia, Journal of Politics and Law, 2(1), https://www.researchgate.net/publication/42386470.

Bilgili, F. ve Şentürk Ulucak, Z.(2018). Socioeconomic Determinants of Crime: An Empirical Application for European Countries. EconWorld2018@Amsterdam, 24-26 July, Amsterdam, Netherlands.

Bukenya, J.O. (2005). Crime Trend and Socio-economic Interactions: A County-level Analysis, Criminal Justice Studies, 18(4), 365-378, DOI: 10.1080/14786010500451265.

Brosnan, S.(2018) The Socioeconomic Determinants of Crime in Ireland from 2003-2012. The Economic and Social Review, 49(2), 127-143.

Elgin, C. (2019). Evolution and Predictors of the Homicide Rate in Turkish Provinces: Evidence from Panel Data. Eur J Crim Policy Res. 25: 379-390.

Elhorts, J. P. (2014). Spatial Econometrics From Cross-Sectional Data to Spatial Panels. Newyork: Springer.

Engle, R.F. ve Granger, C. W. J.(1987). Co-Integration and Error Correction: Representation, Estimation, and Testing. Econometrica, 55(2), 251-276.

Entorf, H. ve Spengler H. (2000). Socioeconomic and Demografic Factors of Crime in Germany Evidence From Panel Data of The German States. International Review of Law and Economics, 20, 75-106.

Glaeser, E. (1999). An Overview of Crime and Punishment Glaeser. Washington: World Bank. Mimeographed.

Gould, E.D., Weinburg, B.A. ve Mustard, D.B. (2002). Crime Rates and Local Labor Market Opportunities in The United States: 1979-1997. The Review of Economics and Statistics. 84(1):45-61, DOI: 10.2139/ssrn.121969.

Hugo, V., Polanco, M. ve Tinoco M.A. (2017) Crime and Regional Economic Growth in Mexico: A spatial Perspective. Papers in Regional Science, 96 (3), doi:10.1111/pirs.12205.

Ishak, S. ve Bani, Y. (2017). Determinants of Crime in Malaysia: Evidence from Developed States. Int. Journal of Economics and Management, 11 (3) : 607-622.

Kizilgol, O. ve S. Selim, (2017). Socio-Economic and Demographic Determinants of Crime by Panel Count Data Analysis: the Case of EU 28 and Turkey. Journal of Business, Economics and Finance (JBEF), 6(1), 31-41. doi.org/10.17261/Pressacademia.2017.383.

Lombardo, R. ve Falcone M. (2011). Crime and Economic Performance. A Cluster Analysis of Panel Data on Italy's NUT3 Regions. Working Papers 201112, Universita della Calabria, Dipartimento di Economia, Statistica e Finanza-DESF.

Moran, P. (1948). Interpretation of Statistical Maps. Biometrica, 255-260.

Shabbir, S., Ali, Q. ve Yaseen, M.R.(2017). Crime and Labor Market: A Panel Data Analysis. European Online Journal of Natural and Social Sciences, 6(3), 343-350.

Taş, N., Doğan, A. ve Önder E. (2014). İşsizlik, Takibe Düşen Kredi ve Boşanma Oranı Değişkenlerinin Suç Sayısı Üzerine Etkisinin Belirlenmesi: Türkiye için Bölgesel Panel Veri Analizi, Niğde Üniversitesi iïBF Dergisi, 7(1), 13-35.

Tunca, H. (2019). Suçun Sosyo-ekonomik Belirleyicileri: Panel Veri Analizi. İnsan ve Toplum Bilimleri Araştırmaları Dergisi, 8(4), 2767-2784. Retrieved from http://www.itobiad.com/tr/issue/49747/602780

TÜik, Bölgesel İstatistikler Veri Tabanı 
Yamak, N., Gürel, F. ve Koçak, S. (2016).Hırsızlık Suçunun Sosyo-Ekonomik ve Demografik Belirleyicileri: Panel Veri Analizi. Tisk Akademi, 57-69.

Yang,W., Chen, B.Y., Cao, X., Li, T. ve Li, P. (2017). The Spatial Characteristics and Influencing Factors of Modal Accessibility Gaps: A Case Study for Guangzhou, China. Journal of Transport Geography, 60, 21-32.

Yorulmaz, Ö. ve Giray Yakut, S. (2017). Türkiye'de Suç Oranını Etkileyen Sosyoekonomik Faktörlerin İncelenmesi: Path Analizine Dayanıklı Yaklaşım. Marmara Üniversitesi İktisadi ve İdari Bilimler Dergisi, 39(1), 307-322. 


\section{THE EFFECT OF SOCIO-ECONOMIC FACTORS ON CRIME: LEVEL-2 REGIONS SPATIAL PANEL DATA ANALYSIS}

\section{Extended Abstract}

Aim: It is generally accepted that socio-economic factors have significant effects on crime. The crime which is one of the important social problems that concern all individuals in a society and therefore the whole country. For this reason, it is important to know these factors, to understand these trends correctly, and to carry out anti-crime programs correctly. Therefore, the aim of the present study to investigates the effect of the per capita gross domestic product, the unemployment rate, the illiterate population, the number of immigration received by regions, rate of the young population, and urbanization rate as variables that affecting crime events. The variables with the largest share in total crimes are included in the sample. These variables include theft and injury crimes. The study covers the period from 2008 to 2018 annually and the Turkish Statistical Classification of Territorial Units (IBBS Level 2) is considered.

Method(s): To determine the relationship between crime and the independent variables it is been used spatial panel model. Spatial regression models include the Spatial Delay Model (SAR), the Spatial Error Model (SEM), the Spatial Durbin Models (SDM), and General Spatial Model (SAC).

The Spatial Delay Model (SAR), which takes into account the spatial delay of the dependent variable, the Spatial Error Model (SEM), where spatial dependence is caused by error terms, the Spatial Durbin models (SDM) which this model is a generalization of the SAR model which also includes spatially weighted independent variables as explanatory variables, and General Spatial Model (SAC) is a model with both spatial error and spatial delay. For panel data, these models can be expanded as fixed effect spatial panel models and random effect spatial panel models.

Findings: It has been carried out the model estimation two different ways: standard panel data model and spatial panel data models. In the model that deals with the theft variable, the appropriate model is determined as the general spatial model (SAC). While the unemployment rate variable has been found to be insignificant in the panel data model with fixed effect, the coefficient of the unemployment rate variable has been found to be negative and statistically significant in the spatial effect panel data model. Other results are parallel and it has been determined that the per capita gross domestic product, urbanization rate, and illiterate rate positively affect the theft crime, while rate of the young population affects negatively. There has no statistically significant effect of migration variable on theft crime in both models. The spatial lag coefficient and spatial autocorrelation coefficient have been found to be positive and statistically significant in the model.

In the injury model, it said that the gross domestic product per capita, the unemployment rate and the urbanization variables have positive and statistically significant in the panel data model with fixed effect but the other variables have been not found to be significant. In the fixed effect spatial panel data model, the SAR, SEM, and SAC models generally have yielded different results. In all three models, the per capita gross domestic product and illiterate variables have statistically significant. In this model, it has determined that the per capita income and illiterate rate positively affected the injury crime. The spatial delay and spatial autocorrelation coefficient in the model have been found to be positive and significant in all three models.

Conclusion: In this context, obtained results the per capita gross domestic product, urbanization rate, and illiterate rate positively affect the theft crime is in line with economic expectations. On the other hand, the young population ratio and unemployment rate negatively affect theft crime. Therefore, an increase happened in these variables causes a decrease in theft crime. Although these results show that the unemployment rate is not in line with the economic expectations in the first impression, it can be said that the result is consistent when it is considered that the unemployment rate is more likely to be by people with a higher education level than those with rural and low education. The variables considered explaining about $90 \%$ of the theft variable. 
In the injury model, the variables of gross domestic product per capita and the rate of illiteracy have been found to be statistically significant in all models. It can be said that an increase in the variable of gross domestic product per capita and the rate of illiteracy may cause an increase in injury crime. 